\title{
"DIRETRIZES ANTECIPADAS DE VONTADE": ESTUDO SOBRE A (IM) POSSIBILIDADE DO SEU RECONHECIMENTO PELO ORDENAMENTO JURÍDICO BRASILEIRO
}

\author{
Iara Lúcia Tcchio Mezomo (D), Marlete Turmina Outeiro (D)2
}

Resumo: Este trabalho tem por objetivo verificar até que ponto a possibilidade da manifestação da vontade dos pacientes em estado terminal é reconhecido como válido no ordenamento jurídico brasileiro. Nesta pesquisa contextualizou-se acerca das diretivas antecipadas (Resolução no 1995/2012), instrumento que pode assegurar a vontade do paciente terminal em morrer com dignidade. Para tanto, foi tratado o conceito e origem das diretivas antecipadas e testamento vital; até que ponto este documento é reconhecido no Brasil. Existem pessoas que são defensores do direito a morte com dignidade, em contrapartida existem aqueles que entendem que ninguém tem o direito de tirar a vida. Diante dessa questão ocorrem conflitos de interesses de opiniões diferenciadas. A Resolução no 1.995 do CFM tentou regularizar as diretivas antecipadas de vontade, mas, não obteve êxito, pois além de não ter força de lei, deixou espaços devido a seu teor ser considerado por demais generalizado. Por conta disso urge o desenvolvimento de um estudo sobre o tema, na tentativa de responder aos questionamentos que são propostos. Os resultados mostram avanços, conforme percebe-se na Resolução no 1.995/2012 do Conselho Federal de Medicina, entretanto evidenciam lacunas referente à necessidade de discutir sobre o testamento em vida, a fim de criar diretrizes e estabelecer seu âmbito de incidência da última vontade do falecido. Ainda assim, o legislador brasileiro precisa se preocupar com o tema "direito de morrer com dignidade", promovendo uma maior segurança jurídica ao paciente, a sua família e também ao profissional de saúde que cumprirá a última vontade diretiva da pessoa em estado terminal.

Palavras-chave: Diretivas Antecipadas; Ortotanásia; Morte Digna.

\section{"EARLY WILL GUIDELINES": STUDY ON THE (IM) POSSIBILITY OF ITS RECOGNITION BY THE BRAZILIAN LEGAL ORDINANCE}

Abstract: This work aims to verify to what extent the possibility of the manifestation of the will of terminally ill patients is recognized as valid in the Brazilian legal system. This research contextualized the advance directives (Resolution no 1995/2012), an instrument that can ensure the terminal patient's will to die with dignity. Therefore, the concept and origin of advance directives and living will were treated; to what extent this document is recognized in Brazil. There are people who are defenders of the right to death with dignity, on the other hand, there are those who understand that no one has the right to take life. Faced with this issue, conflicts of interest arise from different opinions. Resolution No. 1,995

\footnotetext{
${ }^{1}$ Especialista em Gestão Escolar pela Universidade Tecnológica Federal do Paraná (UTFPR). Chefe do Núcleo Regional de Educação de Pato Branco. E-mail: iaramezomo@seed.pr.gov.br.

${ }^{2}$ Mestre em Desenvolvimento Regional pela Universidade Tecnológica Federal do Paraná (UTFPR). Docente da Faculdade Unimater e da Rede Estadual de Ensino. E-mail: marlete.outeiro@gmail.com.
} 
of the CFM tried to regularize the advance directives of will, but it was not successful, as in addition to not having the force of law, it left spaces due to its content being considered too generalized. Because of this, the development of a study on the subject is urgently needed, in an attempt to answer the questions that are proposed. The results show advances, as seen in Resolution No. $1,995 / 2012$ of the Federal Council of Medicine, however they show gaps regarding the need to discuss the living will, in order to create guidelines and establish its scope of incidence of the last will of the deceased. Even so, the Brazilian legislator needs to be concerned with the theme "the right to die with dignity", promoting greater legal security for the patient, their family and also for the health professional who will comply with the last directive will of the terminally ill person.

Keywords: Advance Directives; Orthothanasia; Dignified Death.

\section{Introdução}

Uma das questões levantadas pelos avanços nas técnicas de prolongamento da sobrevida é discussão acerca da denominada ortotanásia, medida ( $\mathrm{n}^{\circ}$ 1995/2012), defendida pelo Conselho Federal de Medicina (CFM), com expressão na Resolução do CFM que passou a valer em 31 de agosto de 2012, como "diretivas antecipadas de vontade".

O art. $1^{0}$ dessa resolução assim se manifesta: "Definir diretivas antecipadas de vontade como o conjunto de desejos, prévia e expressamente manifestados pelo paciente, sobre cuidados e tratamentos que quer, ou não, receber quando estiver incapacitado de expressar, livre e autonomamente, sua vontade" (CFM, 2012).

No Brasil a falta de conhecimento sobre diretrizes antecipadas acaba por permanecer em desuso por grade parte da população. Assim o presente estudo busca fazer com que estudantes do curso de Direito e demais áreas acadêmicas, conheçam o assunto e se interessem pela pesquisa, uma vez que a fragilidade no assunto dificulta a sua aplicabilidade.

Mesmo com as críticas e polêmicas no Brasil, alguns países fizeram adesão ao testamento vital, de forma legal, como EUA, Holanda, Argentina e Portugal. Exemplo de aplicabilidade correta está a Espanha que adota o testamento vital desde o ano de 2000 (PENALVA, 2009).

Dessa premissa, o presente estudo apresenta como problemática: até que ponto a possibilidade da manifestação da vontade dos pacientes em estado terminal é reconhecido como válido no ordenamento jurídico brasileiro?

Com isso, o objetivo verificar até que ponto a possibilidade da manifestação da vontade dos pacientes em estado terminal é reconhecido como válido no ordenamento jurídico brasileiro. Justifica-se a relevância social do presente estudo, porquanto demonstrará através da compreensão e respeito à vida, a doença e as relações humanas dos pacientes em tratamento terminal. Já no nível científico surge a possibilidade de análise, aceitação, diálogo e debate, em relação à ética médica e o desejo do paciente, e no nível pessoal, alegria de viver, estudar, trabalhar e ser voluntária de apoio as pessoas com poucas possibilidades de 
recuperação. O estudo e os resultados poderão trazer esclarecimentos do assunto para a sociedade, para a comunidade científica e para a instituição de ensino.

A metodologia do presente estudo fundamentou-se através de estudo bibliográfico, a partir de pesquisas já realizadas e documentos norteadores.

\section{Da Sucessão Testametária}

O termo sucessão segundo Brito Junior e Ligeiro (2012, p. 4) demanda a transferência da herança ou do legado pela morte, interpretando restritivamente o vocábulo dependendo do evento morte, não vigorando o preceito em que a morte invalida tudo. Ainda sobre a questão de sucessão:

Sucessão em sentido exato é aquela em que os bens de uma pessoa se transmite em razão de sua morte e diz que em sentido amplo é o ato que uma pessoa toma o lugar da outra, substituindo-Ihe em seus direitos (BRITO JUNIOR; LIGEIRO, 2012, p. 4).

Entende-se que a sucessão vem a ser a transferência, do todo ou em parte de herança, por morte de uma pessoa, consistindo em um ou mais herdeiros. Segundo Simões (2008) trata-se da sucessão (direito de herança) pela morte, que subjetivamente concede o direito por força do qual recolhe os bens da herança, e, no conceito objetivo, indica a universalidade dos bens do de cujus, que ficaram com seus direitos e encargos.

Segundo ensinamentos de Miranda (2012) a sucessão hereditária só se abre no momento da morte do indivíduo, com a devida comprovação. Com a abertura da sucessão os herdeiros, legítimos ou testamentários, adquirem, prontamente, a propriedade e a posse dos bens que faz parte do acervo hereditário, sem necessidade de praticar qualquer ato; a sucessão só é aberta se o herdeiro sobrevive ao de cujus, requerendo a apuração da capacidade sucessória.

Verifique-se que é necessário:

Na data da morte do de cujus; daí a importância da exata fixação do dia e da hora do óbito, uma vez que uma precedência qualquer, mesmo de segundos, influi na transmissão do acervo hereditário. O processo de inventário visa descrever e apurar os bens deixados pelo hereditando, a fim de que se proceda à sua partilha entre os sucessores, legalizando, assim, a disponibilidade da herança (MIRANDA, 2012, p. 2).

Ainda segundo Miranda (2012) a Lei decide onde deve ocorrer a abertura da sucessão recorrendo à última residência do falecido, porque entende que aí esteja a sede principal dos interesses e negócios do falecido; a abertura da sucessão no último domicílio determina a competência do foro para os processos referentes à herança (inventário, petição de herança) e para as ações dos co-herdeiros legatários e credores relacionados com os bens da herança.

O sistema jurídico brasileiro estabelece três tipos de sucessores: i) os herdeiros legítimos, os ii) legatários e os iii) testamentários.

\subsection{Herdeiros Legítimos - Legatários - Testamentários}


São considerados herdeiros legítimos aqueles sujeitos definidos em lei, quando for processada a Sucessão Legítima. Têm uma ordem estabelecida no art. 1.829 do Código Civil e correspondem a determinadas regras. São assim chamados por ter o deferimento do seu quinhão estabelecido em lei,

Art. 1829. A sucessão legítima defere-se na ordem seguinte: I - aos descendentes, em concorrência com o cônjuge sobrevivente, salvo se casado este com o falecido no regime da comunhão universal, ou no da separação obrigatória de bens (art. 1.640, parágrafo único); ou se, no regime da comunhão parcial, o autor da herança não houver deixado bens particulares; II - aos ascendentes, em concorrência com o cônjuge; III - ao cônjuge sobrevivente (BRASIL, 2002).

Os herdeiros legítimos são todos aqueles que sucedem o falecido por vontade legal, ou seja, a lei traz em sua envergadura aqueles que são chamados a suceder. Segundo Simões (2008, p. 109) os herdeiros legítimos procedem de determinação legal e dividem-se em:

Herdeiros necessários (descendentes ascendentes e cônjuge). A grande diferença e vantagem de ser herdeiro necessário, é que estes têm direito a legítima, ou seja, Ihes são assegurados $50 \%$ (metade) do patrimônio do sucessor. Herdeiros facultativos: (colaterais até 40 grau e companheiro). Essa obrigatoriedade de receber $50 \%$ dos bens/direitos/obrigações aponta que o sistema jurídico brasileiro adotou o entendimento de que é exclusiva aos herdeiros necessários uma parte da herança, da qual não pode seu titular dispor de destinação diversa (SIMÕES, 2008, p. 8 - grifo do autor).

Em suma, os herdeiros legítimos são os sujeitos que sucedem ao falecido. No próximo item será tratado sobre os herdeiros legatários. Os herdeiros legatários recebem exclusivamente o que Ihes foi deixado em testamento, herdando apenas um bem em específico, não sendo proibido que seja estabelecido um herdeiro necessário ou um terceiro alheio à ordem vocação. Segundo Simões (2008, p. 110), todavia, esse alheio, pode ser um filho que não esteja vinculado por laços de sangue, mas por laços de afeto.

Herdeiros testamentários são aqueles que têm seu quinhão definido e deferido através de testamento feito pelo testador (SIMÕES, 2008).

\subsection{Sucessão Testamentária}

A sucessão testamentária tem por embasamento a disposição de última vontade do testador que segundo Gontijo (2008) ocorre por testamento. Por esse motivo, ao regular a sucessão testamentária, limita-se ao trato do testamento.

O testamento, como forma imponente de manifestação de última vontade é a instituição em que se fundamenta a sucessão testamentária que tem por finalidade substituir parcial ou totalmente a sucessão legítima, com disposições positivas ou negativas referentes à herança, ainda que dele possam constar, até mesmo, disposições sobre direito de família, das obrigações ou das coisas.

De acordo com o Código Civil arts. 1.857 e 1.858 o testamento vital constitui: 
Art. 1.857. Toda pessoa capaz pode dispor, por testamento, da totalidade dos seus bens, ou de parte deles, para depois de sua morte.

Art. 1.858. O testamento é ato personalíssimo, podendo ser mudado a qualquer tempo (BRASIL, 2002).

Ou seja, o testamento vital constitui-se a partir do ato de última vontade, pelo qual o possuidor da herança dispõe de seus bens para depois da morte e faz outras disposições, sendo considerado pelo Código Civil (art. 1.858) ato personalíssimo e revogável pelo qual alguém dispõe da totalidade dos seus bens, ou parte deles, para depois de sua morte.

\subsection{Testamento Vital ou Diretivas Antecipadas}

Primeiramente cabe realizar comentário sobre a adequação da denominação utilizada na Resolução CFM 1955/2012, para esta situação: diretivas antecipadas de vontade. Segundo Goldim (2012, p. 1) "[...] existem diversas maneiras de denominar esta mesma questão: manifestação explícita da própria vontade, testamento vital, biotestamento, testamento biológico, diretivas avançadas, vontades antecipadas, entre outras".

$\mathrm{Na}$ atualidade a medicina vem evoluindo num ritmo acelerado em relação a tratamentos que prolongam a vida dos pacientes, ampliando as discussões acerca dos direitos do paciente em manifestar a sua vontade, seu desejo ou não para tratamentos terapêuticos. Essa manifestação de vontade corrobora para constituir um instrumento que expresse o interesse ou não do paciente ser submetido a tratamento médico, no qual garanta mesmo na incapacidade civil o seu desejo a qual tratamento médico será submetido, pois é válido para pacientes em estágio terminal.

O conceito de testamento vital vem sendo amplamente debatido no Brasil e recebe nomes como diretivas antecipadas e ou testamento em vida. A autonomia do paciente nas diretivas antecipadas da vontade pode ser realizada através do testamento em vida, documento a qual o paciente dispõe em vida os liames da sua própria consciência a que tipo de tratamento médico será submetido ou recusa, se estiver inconsciente e não puder exprimir sua própria vontade.

As diretivas antecipadas (advanced care documents), tradicionalmente, têm sido entendidas como o gênero do qual são espécies a declaração prévia de vontade do paciente terminal (living will) e o mandato duradouro (durable power attorney). Ambos os documentos serão utilizados quando o paciente não puder, livre e conscientemente, se expressar - ainda que por uma situação transitória -, ou seja, as diretivas antecipadas, como gênero, não se referem exclusivamente a situações de terminalidade (PENALVA, 2009, p. $54)$.

No Brasil testamento se refere pós-morte, não sendo a nomenclatura apropriada testamento vital, pois tem eficácia em vida. Nesse sentido Penalva (2009) sugere a nomenclaturadeclaração prévia de vontade.

Portanto, as diretivas antecipadas garantem manifestações da vontade do indivíduo com autonomia particular e de forma dignidade, buscando evitar ao 
paciente terminal submissão a tratamento médico indesejado, concomitante a inconsciência ou incapacidade.

Compreende-se por testamento vital:

Documento formalizado e escrito por pessoa em livre consciência, ou seja, capaz, objetivando a expressa autonomia de sua vontade para dispor a qual tratamento ou não que será submetido, diante de situação de saúde terminal, irreversível ou incurável. Mesmo que incapaz, estando formalizado documento terá sua autonomia decisória (PENALVA, 2009, p. 54).

No mesmo sentido Dias (2013, p. 385), cita em sua obra Manual das Sucessões: "Testamento vital é o documento que contém disposições sobre a assistência médica a ser prestada a paciente terminal".

\section{Metodologia}

A metodologia do presente estudo deu-se sob a perspectiva dedutiva, partindo de uma contextualização geral para se chegar à verdade daquilo que se conjetura. Quanto aos objetivos o presente estudo foi classificado como pesquisa descritiva, que segundo Gil (2002, p. 42) "tem como objetivo fundamental a descrição de características de determinada população".

No que diz respeito à coleta de dados, foram utilizadas fontes bibliográficas. Que segundo Ruaro (2004, p. 8) incide em: "materiais escritos que contenham informações já elaboradas e publicadas por outros autores". O método bibliográfico foi apropriado, isto porque possibilita a pesquisadora ter diversas fontes de informação escrita sobre o tema abordado. Diante da seriedade que o tema enseja a pesquisadora, certificou-se das condições em que os dados foram coletados, analisou as para detectar possíveis contradições e utilizou fontes diversas, verificando-as com a devida atenção (GIL, 2002).

\section{Resultados e discussões}

O testamento vital "é uma espécie de diretiva antecipada de vontade, que possibilita ao elaborador registrar em um documento a que tratamentos médicos se submeteria ou não em caso de doença terminal" (REVISTA SÍNTESE DIREITO DE FAMÍLIA, 2012, p. 72).

\subsection{Resolução No 1.995/2012 do Conselho Federal De Medicina}

A nomenclatura testamento vital tem recebido críticas por se tratar, muito mais, de uma tradução literal do instituto americano do living will (testamento vital) do que necessariamente de sua natureza jurídica. De fato, existem paridades entre o denominado testamento vital e o testamento previsto no Código Civil brasileiro, sendo, apesar disso, "indispensável registrar que o testamento vital não possui efeito post mortem, nem se trata de documento solene, como o é o testamento propriamente dito" (REVISTA SÍNTESE DIREITO DE FAMÍLIA, 2012).

A Constituição Federal prevê-nos (art. 10, III) os princípios da dignidade da pessoa humana e no (art. $5^{\circ}$ ) a autonomia da pessoa, e implícito no (art. 50, III) 
a expressa proibição de tratamento desumano, contidos nesses artigos a defesa suficiente da declaração prévia da vontade do paciente terminal, dispõe de aceitação de tratamento ou recusa, que em caso de terminalidade de vida pode ser expressa em documento.

Requer primeiramente que o indivíduo tenha capacidade plena, maior de (dezoito) 18 anos, com comprovação de discernimento para tal efeito jurídico, precisa ter assinaturas e duas testemunhas, com registro em cartório, para ter fé pública, tendo a mesma formalidade do testamento público.

Em 17 de março de 1999, no Estado de São Paulo criou-se a Lei Estadual de no 10.241 que dispões de 24 incisos, que trata sobre os direitos e ações de saúde dos pacientes.

A Lei 10.2411999 é desfavorável no sentido de prolongar a vida com circunstâncias que venha ferir a dignidade do paciente, oportunizando ao paciente ou seu representante ao que deseja, de modo que o paciente conduza de maneira digna o final da vida. Com a presente Lei surgiu à adoção de medidas paliativas, auxiliando o atendimento domiciliar, cuidando o paciente terminal em casa, buscando respeitar o direito das pessoas, com a garantia digna do seu viver e no seu morrer.

Do mesmo intuito da Lei Estadual de São Paulo, a Resolução no 1.995/2012 pelo Conselho Federal de Medicina (CFM) foi aprovada com incisos e artigos semelhantes. Tornando possível através da Resolução o reconhecimento do sistema do Testamento Vital no Brasil, mesmo com muitas barreiras legislativas e interpretações contrarias a sua aplicação.

DIREITO CIVIL. ASSINATURA DO TESTADOR COMO REQUISITO ESSENCIAL DE VALIDADE DE TESTAMENTO PARTICULAR. Será inválido o testamento particular redigido de próprio punho quando não for assinado pelo testador. De fato, diante da falta de assinatura, não é possível concluir, de modo seguro, que o testamento escrito de próprio punho exprime a real vontade do testador. A propósito, a inafastabilidade da regra que estatui a assinatura do testador como requisito essencial do testamento particular (art. 1.645, I, do CC/1916 e art. 1.876, § $10, \mathrm{CC} / 2002$ ) faz-se ainda mais evidente se considerada a inovação trazida pelos arts. 1.878 e 1.879 do CC/2002, que passaram a admitir a possibilidade excepcional de confirmação do testamento particular escrito de próprio punho nas hipóteses em que ausentes às testemunhas, desde que, frise-se, assinado pelo testador. Notase, nesse contexto, que a assinatura, além de requisito legal, é mais que mera formalidade, consistindo em verdadeiro pressuposto de validade do ato, que não pode ser relativizado. REsp 1.444.867-DF, Rel. Min. Ricardo Villas Bôas Cueva, julgado em 23/9/2014.

Sendo assim, a Resolução 1.995/2012 do Conselho Federal de Medicina (FM) está aprovada e se mostra válida e merece apresentação na integra para plena compreensão:

Art. $1^{\circ}$ Definir diretivas antecipadas de vontade como o conjunto de desejos, prévia e expressamente manifestados pelo paciente, sobre cuidados e tratamentos que quer, ou não, receber no momento em que estiver incapacitado de expressar, livre e autonomamente sua vontade. Art. $20 \mathrm{Nas}$ decisões sobre cuidados e tratamentos de pacientes que se encontram incapazes de comunicar-se, ou de expressar de maneira livre e independente 
suas vontades, o médico levará em consideração suas diretivas antecipadas de vontade. $\S 1^{\circ}$ Caso o paciente tenha designado um representante para tal fim, suas informações serão levadas em consideração pelo médico.

$\S 200$ médico deixará de levar em consideração as diretivas antecipadas de vontade do paciente ou representante que, em sua análise, estiverem em desacordo com os preceitos ditados pelo Código de Ética Médica. $\S 30$ As diretivas antecipadas do paciente prevalecerão sobre qualquer outro parecer não médico, inclusive sobre os desejos dos familiares. § 400 médico registrará, no prontuário, as diretivas antecipadas de vontade que lhes foram diretamente comunicadas pelo paciente. $\S 5^{\circ}$ Não sendo conhecidas as diretivas antecipadas da vontade do paciente, nem havendo representante designado, familiares disponíveis ou falta de consenso entre estes, o médico recorrerá ao Comitê de Bioética da instituição, caso exista, ou, na falta deste, a Comissão de Ética Médica do hospital ou ao Conselho Regional e Federal de Medicina para fundamentar sua decisão sobre conflitos éticos, quando entender esta medida necessária e conveniente. Art. $3^{\circ}$ Esta Resolução entra em vigor na data de sua publicação.

Portanto, mesmo com falhas, o testamento vital não é recente, pois já existe este reconhecimento na prática, e a formalização deste documento tem amparo legal perante a justiça, que decidirão amparados na lei. Dessa forma a vontade do paciente tem amparo de uma Resolução e a carência de lei específica, não suspende tal ato.

O ordenamento jurídico brasileiro protege a pessoa através dos princípios fundamentais, da dignidade e respeito à pessoa humana, da autonomia da vontade, do princípio da liberdade, do direito a intimidade e ainda a proibição de tratamento desumano, ambos constam no Artigo $5^{\circ}$ da Constituição Federal. Antes de analisar as situações que trazem possibilidades da elaboração do testamento, é necessário fazer certas considerações pontuais sobre sua regulamentação no Brasil.

Atualmente, não existe no Brasil legislação regulamentando o testamento vital. Não há, portanto, lei específica que delimite as formalidades e os requisitos necessários para sua elaboração. Contudo, o Conselho Federal de Medicina, tentando regulamentar, no âmbito médico, as diretivas antecipadas de vontade, editou a Resolução no 1.995/2012, tendo se referido ao testamento vital em seu art. $1^{\circ}$ e ao mandato duradouro no $\S 1^{\circ}$ do art. $2^{\circ}$.

Tem-se que reconhecer que a Resolução no 1.995/2012, caracteriza-se como um avanço no que diz respeito ao tratamento das diretivas antecipadas de vontade no Brasil e:

E um importante passo para elaboração de futura lei regulamentadora da matéria. A resolução, contudo, precisa ser aprimorada, tendo em vista a existência de lacunas que dificultam o entendimento e aplicação do instituto. Futura lei, por exemplo, precisará, sob pena de regulamentação genérica do testamento vital, regulamentar questões como legitimidade para elaboração, prazo de validade, forma documental (precisa lavrar escritura pública?), forma de representação, entre outras (REVISTA SÍNTESE DIREITO DE FAMÍLIA, 2013, p. 74).

A constitucionalidade da resolução 1.995/2012, ainda está sendo questionada pelo Ministério Público Federal de Goiânia, por meio da Ação Civil Pública (no 0001039-86.2013.4.01.3500), sob o embasamento de violação, 
A constitucionalidade da resolução 1.995/2012, ainda está sendo questionada pelo Ministério Público Federal de Goiânia, por meio da Ação Civil Pública (nº 0001039-86.2013.4.01.3500), sob o embasamento de violação,

Por parte do Conselho Federal de Medicina, dos "lindes da disciplina ética da medicina, notadamente por transcenderem a relação médico/paciente. 0 tema subjacente à aludida regulamentação possui repercussões familiares, sociais e nos direitos de personalidade, que escampam ao poder de normatização do réu". Além do mais, afirma o Ministério Público que a resolução é omissa, não prevendo situações elementares para a segurança jurídica (AÇÃO CIVIL PÚBLICA, nº 0001039-86.2013.4.01.3500).

Frente a essas conclusões, o Ministério Público de Goiânia pleiteou liminarmente a declaração incidental da inconstitucionalidade da Resolução no 1.995 do CFM, com a suspensão de sua aplicação em todo o território nacional, bem como fosse proibido ao Conselho Federal de Medicina expedir ato normativo que extrapole os limites de seu poder regulamentar.

Destaque-se que o pedido liminar foi recusado pelo juiz da $1^{\circ}$ Vara Federal de Goiás, que garantiu, em análise inicial, que não há inconstitucionalidade a ser declarada, não tendo advindo excesso por parte do Conselho Federal de Medicina ao editar a aludida resolução. Diante do apresentado, é importante citar na íntegra dois trechos dessa decisão:

[...] o Conselho Federal de Medicina não extrapolou os poderes normativos outorgados pela Lei no 3.268/1957, tendo a Resolução CFM no 1.995 apenas regulamentados a conduta ética médica perante a situação fática de o paciente externar a sua vontade quanto aos cuidados e tratamentos médicos que deseja receber ou não na hipótese de encontrar em estado terminal e irremediável. [...] a Resolução é constitucional e se coaduna com o princípio constitucional da pessoa humana, uma vez que assegura ao paciente em estado terminal, o recebimento de cuidados paliativos, sem o submeter, contra a sua vontade, a tratamentos que o prolonguem o seu sofrimento e não tragam mais qualquer benefício (JUIZ da $1^{\text {a }}$ VARA FEDERAL DE GOIÁS).

Para Dadalto (2013) essa decisão, mesmo se tratando de uma liminar, é um marco no Direito brasileiro, uma vez que, pela primeira vez, o Judiciário reconhece o poder de autodeterminação dos enfermos em estágio terminal de vida, manifestando-se expressamente sobre a dignidade da pessoa humana.

Diante do que foi apresentado, verifica-se que a previsão do testamento vital na Resolução no 1.995/2012 do Conselho Federal de Medicina conseguiu avançar no estudo sobre este instituto. Entretanto, as lacunas existentes deixam evidências sobre a necessidade de se discutir mais amplamente sobre o testamento vital, criando suas diretrizes e estabelecendo seu âmbito de incidência.

\section{Considerações finais}

Realizou-se no presente estudo uma breve abordagem acerca das diretivas antecipadas, as formas e instrumentos que asseguram a vontade do paciente terminal morrer com dignidade. Para tanto, o estudo apresentou o conceito e 
origem dessas diretivas antecipadas, em que situações e momentos pode ser aplicado, o projeto de Lei que pode vir a validar.

O Conselho Federal de Medicina mais uma vez vem demandando esforços em tentar admitir autonomia de vontade a esses pacientes terminais, pelo menos foi o que propôs na Resolução no. 1995/2012, já que não existe nenhuma regulamentação legal acerca desse assunto.

A Resolução no 1.995 do CFM tentou regularizar as diretivas antecipadas de vontade, mas, não logrou êxito, pois além de não ter força de lei, deixou espaços devido a seu teor ser considerado por demais generalizado. Por conta disso, urge o desenvolvimento de um estudo sobre o tema, na tentativa de responder aos questionamentos que são propostos.

Diante da inquietude jurídica dos profissionais médicos e com as lacunas e má interpretação da resolução dificulta a emissão de leis normativas que proporcione segurança jurídica aos profissionais. Diante do que foi apresenta evidencia-se que o legislador brasileiro precisa se preocupar com o tema "direito de morrer com dignidade", promovendo assim uma maior segurança jurídica ao paciente, a sua família e também ao profissional de saúde que cumprirá a última vontade diretiva da pessoa em estado terminal.

Parece correto afirmar que a Resolução CFM n.o 1.995/2012 não almeja introduzir no ordenamento jurídico brasileiro a possibilidade de se facultar ao paciente a possibilidade de se valer da ortotanásia. A finalidade da mencionada Resolução é somente informar ao médico que o procedimento ético da profissão está em conformidade com a necessidade de se respeitar os desejos e vontades previamente proclamados pelo paciente em estado terminal.

Verificou-se diante das literaturas apresentadas que a declaração prévia de vontade do paciente terminal é instrumento que garante a autonomia e da dignidade deste, não obstante não estar legalizado expressamente no Brasil, a interpretação de normas constitucionais e infraconstitucionais possibilita chegar à conclusão que é válido. No entanto, verificou-se a necessidade de definição dos elementos eficazes desse instrumento, como conteúdo e questões formais.

\section{REFERÊNCIAS}

BRASIL. Código Civil Brasileiro. Lei no 10.406, de 10 de Janeiro de 2002.

Disponível em://www.planalto.gov.br/ccivil_03/Leis/2002/L10406.htm. Acesso em: 15 abr. 2015.

BRASIL. Constituição Federal. Disponível em:

http://www.planalto.gov.br/ccivil_03/Leis/2002/L10406.htm. Acesso em: 12 abr. 2015.

BRITO JÚNIOR, Gilberto Fernandes; LIGEIRO, Gilberto Notário. Direito das sucessões: conceito e considerações, bem como evolução na linha do tempo: delimitação das margens históricas do direito das sucessões (2012). Disponível em: http://intertemas.unitoledo.br/revista/index. php/ETIC/article/viewFile/2526/2050. Acesso em: 26 abr. 2015. 
CARVALHO, Adriana Pereira Dantas. Direito de morrer de forma digna: autonomia da vontade (2013). Disponível em: http://www.idbfdul.com/uploaded/files/2013_02_01009_01028.pdf. Acesso em: 26 abr. 2015.

CONSELHO FEDERAL DE MEDICINA. Resolução no. 1.805/2006. Brasília: CFM, 2006. Disponível em: http://portal.cfm.org.br/. Acesso 26 abr. 2015.

CONSELHO FEDERAL DE MEDICINA. Resolução no. 1.931/2009. Brasília: CFM, 2009. Disponível em: http://portal.cfm.org.br/. Acesso 26 abr. 2015.

DA SILVA, José Afonso. Curso de Direito Constitucional Positivo. 36. ed. Revista e atualizada até a Emenda Constitucional n. 71, de 29.11.2012. Malheiros Editores São Paulo.

DIAS, Maria Berenice. Manual de direito sucessões. São Paulo: Saraiva 2013.

DINIZ, Maria Helena Diniz. O estado atual do Biodireito. 3a. Ed. São Paulo: Ed. Saraiva 2006. GIL. Antonio Carlos. Como elaborar projetos de pesquisa. $4^{a}$. Ed. São Paulo: Atlas, 2002.

GOLDIM, José Roberto. Diretivas antecipadas de vontade comentários sobre a resolução 1955/2012 do Conselho Federal De Medicina/Brasil. Disponível em: http://www.ufrgs.br/bioetica/diretivas2012.pdf. Acesso em: 10 dez. 2015.

GOMES, Henriette Ferreira. O conceito de informação pelo viés da alteridade. Tendências da pesquisa brasileira em ciência da informação, v.7, n.1, jan./jun. 2014.

GONTIJO, Juliana. Sucessão testamentária (2008). Disponível em: http://www.gontijofamilia.adv.br/2008/paginas/Material\%20didatico/Sucessoes \%20- \%20sucessao\%20testamentaria. pdf. Acesso em: 10 abr. 2015.

LOTUFO, Renan. (Coord.) Cadernos de direito civil constitucional. Curitiba: Juruá, 2001.

MARINELI, Marcelo Romão. A declaração de vontade do paciente terminal: as diretivas antecipadas de vontade à luz da Resolução 1.995/2012 do Conselho Federal de Medicina. Disponível em:

http://ambitojuridico.com.br/site/?n_link=revista_artigos_leitura\&artigo_id=138 32. Acesso em: 10 mar. 2015.

MIRANDA, Maria Bernadete. Direito das sucessões. Parte II. Direito Brasil. Publicações (2012). Disponível em:

http://www.direitobrasil.adv.br/arquivospdf/revista/revistav51/aulas/DSII.pdf. Acesso em: 10 nov. 2012. 
NOGUEIRA, Paulo Lúcio. Em defesa da vida: aborto, eutanásia, pena de morte, suicídio, violência, linchamento. São Paulo: Saraiva 1995.

PENALVA, Luciana Dadalto. Decisão Liminar na Ação Civil Pública 000103986.2013.4.01.3500: Suspensão da Resolução no 1.995/2012 (Direito do Paciente de Fazer suas Diretivas Antecipadas de Vontade, Independente da Vontade de seus Familiares e o Dever do Médico de Respeitar a Vontade Manifestada nessas Diretivas). Revista Brasileira de Direito das Famílias e Sucessões, v.33, p. 113-124, 2013.

PENALVA, Luciana Dadalto. Declaração prévia de vontade do paciente terminal. 2015. 183f. Dissertação (Mestrado em Direito) - Universidade Católica de Minas Gerais, (2009) Disponível em http://www.biblioteca.pucminas.br/teses/Direito_PenalvaLD_1.pdf. Acesso em: 12 mar. 2015.

PENALVA, Luciana Dadalto. Distorções acerca do testamento vital no Brasil (ou o porquê é necessário falar sobre uma declaração prévia de vontade do paciente terminal). Revista de Bioética y Derecho, núm. 28, mayo 2013, p. 61-71. Disponível em: Acesso em: 12 jan. 2015.

PENALVA, Luciana Dadalto. Reflexos jurídicos da resolução CFM 1995/2012. Revista Bioética, v. 21, p. 106-112, 2013.

PENALVA, Luciana Dadalto. Testamento vital. 2a. Ed. Rio de Janeiro: Lumen Juris, 2013.

PESSINI, Léo. A eutanásia na visão das grandes religiões mundiais. Revista do Conselho Regional de Medicina n. 1, v. 7, 2001.

REVISTA SÍNTESE DIREITO DE FAMÍLIA. Continuação da Revista IOB de Direito de Família - v.14, n. 74, out./nov. 2012.

REVISTA SÍNTESE DIREITO DE FAMÍLIA. Continuação de Revista IOB de Direito de Família - v.15, n. 80, out./nov. 2013.

RUARO, Dirceu Antônio. Manual de apresentação de produção acadêmica: pesquisa, textos acadêmicos, apresentação de trabalhos. 2a. Ed. Pato Branco: Faculdade Mater Dei, 2004. SÁ, Maria de Fátima Freire. Biodireito e direito ao próprio corpo. Belo Horizonte: Del Rey, 2005.

SANTANA, Angélica. Princípios fundamentais do direito contratual. Revista NPI/FMR - Núcleo de Pesquisa Interdisciplinar. Disponível em: http://www.fmr.edu.br/npi/npi_direito_contratual.pdf. Acesso em: 26 abr. 2015.

SCALQUETTE, Ana Claudia Silva. 60 desafios do direito: direito na sociedade contemporânea. São Paulo: Atlas, 2013. 
SILVA, Jonathas Luiz Carvalho; SIMÕES, Thiago Felipe Vargas. A filiação socioafetiva e seus reflexos no direito sucessório. São Paulo: Editora Fiuza, 2008.

SIQUEIRA-BATISTA, Rodrigo; SCHRAMM, Fermin Roland. Conversações sobre a "boa morte": o debate bioético acerca da eutanásia. Cad. Saúde Pública. 2005, vol.21, n.1, pp. 111-119. Disponível em

http://www.scielo.br/pdf/csp/v21n1/13.pdf. Acesso em: 16 dez. 2015.

TAVARES, André Ramos. Curso de direito constitucional. 6a. Ed. São Paulo: Saraiva 2008.

Recebido em: 11 de janeiro de 2021.

Aceito em: 29 de abril de 2021. Publicado em: 15 de dezembro de 2021. 